\title{
High Risk of Seizures and Epilepsy after Decompressive Hemicraniectomy for Malignant Middle Cerebral Artery Stroke
}

\author{
Rosane Brondani ${ }^{a-c} \quad$ Andrea Garcia de Almeida ${ }^{a-c}$ Pedro Abrahim Cherubini ${ }^{b, c}$ \\ Suelen Mandelli Mota ${ }^{b}, c$ Luiz Carlos de Alencastro ${ }^{d}$ \\ Apio Cláudio Martins Antunes ${ }^{\mathrm{e}}$ Marino Bianchin Muxfeldt ${ }^{\mathrm{a}-\mathrm{c}, \mathrm{f}}$ \\ a Postgraduate Program in Medicine: Medical Science, Universidade Federal do Rio Grande do \\ Sul, Porto Alegre, Brazil; b Basic Research and Advanced Investigations in Neurology (B.R.A.I.N.), \\ Hospital de Clínicas de Porto Alegre, Universidade Federal do Rio Grande do Sul, Porto Alegre, \\ Brazil; ' ${ }^{c}$ Division of Neurology, Hospital de Clínicas de Porto Alegre, Porto Alegre, Brazil; \\ dDivision of Neurosurgery, Hospital Mãe de Deus, Porto Alegre, Brazil; e Division of Neurosurgery, \\ Hospital de Clínicas de Porto Alegre, Universidade Federal do Rio Grande do Sul, Porto Alegre, \\ Brazil; ${ }^{f}$ Center for Treatment of Drug Refractory Epilepsy (CETER), Hospital de Clínicas de \\ Porto Alegre, Porto Alegre, Brazil
}

Keywords

Stroke $\cdot$ Risk factors for seizures - Risk factors for epilepsy $\cdot$ Seizure prophylaxis · Post-stroke epilepsy

\section{Abstract}

Background: Decompressive hemicraniectomy (DHC) is a life-saving procedure for treatment of large malignant middle cerebral artery (MCA) strokes. Post-stroke epilepsy is an additional burden for these patients, but its incidence and the risk factors for its development have been poorly investigated. Objective: To report the prevalence and risk factors for post-stroke seizures and post-stroke epilepsy after DHC for treatment of large malignant MCA strokes in a cohort of 36 patients. Methods: In a retrospective cohort study of 36 patients we report the timing and incidence of post-stroke epilepsy. We analyzed if age, sex, vascular risk factors, side of ischemia, reperfusion therapy, stroke etiology, extension of stroke, hemorrhagic transformation, ECASS scores, National Institutes of Health Stroke Scale (NIHSS) scores, or modified Rankin scores were risk factors for seizure or epilepsy after DHC for treatment of large MCA strokes. Results: The mean patient follow-up time was 1,086 days (SD = 1,172). Out of 36 patients, 9 (25.0\%) died before being discharged. After 1 year, a total of 11 patients (30.6\%) had died, but 22 (61.1\%) of them had a modified Rankin score $\leq 4$. Thirteen patients (36.1\%) developed seizures within the first week after stroke. Seizures occurred in 22 (61.1\%) of 36 patients (95\% CI = 45.17-77.03\%). Out of 34 patients who survived the acute period, 19 (55.9\%) 
developed epilepsy after MCA infarcts and DHC (95\% CI = 39.21-72.59\%). In this study, no significant differences were observed between the patients who developed seizures or epilepsy and those who remained free of seizures or epilepsy regarding age, sex, side of stroke, presence of the clinical risk factors studied, hemorrhagic transformation, time of craniectomy, and Rankin score after 1 year of stroke. Conclusion: The incidence of seizures and epilepsy after malignant MCA infarcts submitted to DHC might be very high. Seizure might occur precociously in patients who are not submitted to anticonvulsant prophylaxis. The large stroke volume and the large cortical ischemic area seem to be the main risk factors for seizure or epilepsy development in this subtype of stroke.

(C) 2017 The Author(s)

Published by S. Karger AG, Basel

\section{Introduction}

Stroke is the second most common cause of mortality and the major cause of disability in the world [1]. It is also a common cause of epilepsy [2-5]. In patients older than 65 years, stroke is the main cause of newly diagnosed epilepsy [6, 7]. As the prevalence of post-stroke epilepsy increases with age [8], and worldwide life expectancy is increasing, post-stroke epilepsy prevalence tends to increase, affecting a growing number of individuals for a longer period of time. Post-stroke seizures or post-stroke epilepsy are additional burdens for stroke patients, increasing stroke morbidity and mortality [9]. Antiepileptic drugs might decrease cognition and rehabilitation, having an impact in the long-term quality of life of these patients $[10,11]$.

Stroke is not a homogeneous pathology, and characteristics of stroke subtypes substantially affect the risks and forms of post-stroke seizures and epilepsy [12]. Good examples are the large middle cerebral artery (MCA) strokes, which have been associated with high rates of seizures and epilepsy. The diagnosis of MCA infarction is usually based on typical clinical presentation, development, and neuroimaging findings. Patients with subtotal or complete MCA infarctions typically present with head and eye deviation, paralysis of one side of the body, severe sensory deficits, and global aphasia when the dominant hemisphere is compromised [13]. Patients with malignant MCA infarctions show a progressive deterioration of consciousness over the first 24-48 h and commonly have a reduced ventilatory drive, requiring mechanical ventilation [13]. No medical treatment has been proven effective for malignant MCA ischemic stroke [14]. Decompressive surgery undertaken within $48 \mathrm{~h}$ of stroke onset reduces mortality and increases the number of patients with a favorable functional outcome [15]. As far as we know, only 2 previous studies were conducted to specifically investigate the incidence of and the risk factors for seizure or epilepsy in malignant stroke of the MCA $[16,17]$. Here, we report the results of a retrospective cohort study of 36 patients with malignant stroke of the MCA submitted to decompressive hemicraniectomy (DHC), analyzing the incidence of and the risk factors for seizure or epilepsy development in these patients. We believe these results might contribute to the understanding of the characteristics and risk factors for seizures in patients with large MCA strokes, aiding in the planning of new treatment strategies for post-stroke epilepsy in this group of patients.

\section{Material and Methods}

\section{Patients}

After approval by the Ethics Committee of our institutions, we selected all patients submitted to DHC for malignant stroke of the MCA from March 2003 to January 2015. Thirtysix patients were eligible and included in this study. Variables studied included age, sex, side 
of stroke, presence of clinical pathologies, hemorrhagic transformation, time of craniectomy, and Rankin score after 1 year. Patients were classified into different groups according to the presence of seizures or post-stroke epilepsy, and variables were compared to investigate risk factors for seizures or epilepsy. A patient was considered to have a seizure if the event was witnessed and the description was compatible with a focal or generalized seizure. In those patients who were in hospital or in those in whom that event was not clear enough, a prolonged EEG was obtained in order to improve diagnosis accuracy. A patient was considered to have epilepsy according with definitions of the ILAE [18]. Patients with epilepsy were defined as (1) those who experienced 1 or more seizures and if their EEG showed unequivocal epileptiform abnormalities; and (2) patients who had to be treated chronically with anticonvulsant drugs or if antiepileptic drugs had to be reintroduced after they had been discontinued because of seizure recurrences. The protocol was approved by the Ethics Committee of our institutions and was conducted according to the principles expressed in the Declaration of Helsinki. Our study is in accordance with the STROBE requirements.

\section{Surgical Procedures}

Patients with large MCA territory ischemic strokes and with risk of herniation were offered a DHC at our institutions during the first $72 \mathrm{~h}$, but seeking the procedure in the first $48 \mathrm{~h}$ after stroke. In our cohort, most patients were submitted to DHC within the first $48 \mathrm{~h}$ from stroke onset. Decompressive surgery was performed according to what is recommended in the literature [19]. No prophylactic anticonvulsant therapy was used, and patients received antiepileptic drugs only if they presented seizures.

\section{Statistical Analysis}

Categorical data were compared using the Fisher exact test, and results are expressed in odds ratios and $95 \%$ confidence intervals (CI). Numerical variables were compared using the Student independent $t$ test, and results are expressed in means and standard deviations (SD). Kaplan-Meier survival analysis was used to express development of seizures during time of patient follow-up. Results were considered significant if $p<0.05$. The software IBM SPSS Statistics version 20.0 was used for statistical analysis.

\section{Results}

The mean patient follow-up time was 1,086 days (SD =1,172). Patients' characteristics are presented in Table 1. The mean age of the patients was 58.9 years ( $\mathrm{SD}=11.9$ ). DHC was performed during the first $24 \mathrm{~h}$ in 16 patients (44.4\%), between 24 and $48 \mathrm{~h}$ in 13 patients (36.1\%), and between 48 and $72 \mathrm{~h}$ in 6 patients $(16.7 \%)$. One patient $(2.8 \%)$ was submitted to DHC after $72 \mathrm{~h}$ of stroke onset. Seizures occurred in 22 out of 36 patients (61.1\% of patients, $95 \% \mathrm{CI}=45.17-77.03 \%)$, with a mean time for occurrence of 35.0 days (SD $=56.2$ ). Out of 34 patients (95\% CI $=39.21-72.59 \%$ ) who survived the acute period, 19 (55.9\%) developed epilepsy. Figure 1 shows the frequency of epileptic seizures and epilepsy in our study compared to the studies by Creutzfeldt et al. [16] and Santamarina et al. [17].

No significant differences were observed between the 22 patients who developed seizures and those who remained without seizures regarding age, sex, side of stroke, presence of the clinical risk factors studied, hemorrhagic transformation, time of craniectomy, and Rankin score 1 year after stroke (Table 2). With similar results, no significant differences were observed between the 19 patients who developed epilepsy and those who remained without epilepsy regarding age, sex, side of stroke, presence of the clinical risk factors studied, hemorrhagic transformation, time of craniectomy, and Rankin score 1 year after stroke (data not 


\section{Cerebirovascular \\ Diseases}

Table 1. Characteristics of patients $(n=36)$

\begin{tabular}{l}
\hline Cerebrovasc Dis Extra \\
\hline DOI: $10.1159 / 000458730$ \\
\hline
\end{tabular}

Brondani et al.: High Risk of Seizures and Epilepsy after DHC for Malignant MCA Stroke

\begin{tabular}{|c|c|}
\hline Mean age $\pm S D$, years & $58.9 \pm 11.9$ \\
\hline Female & $17(47.2)$ \\
\hline Male & $19(52.8)$ \\
\hline Caucasian & $33(91.7)$ \\
\hline \multicolumn{2}{|l|}{ Vascular risk factors } \\
\hline Hypertension & $31(86.1)$ \\
\hline Diabetes mellitus & $10(27.8)$ \\
\hline Hypercholesterolemia & $6(16.7)$ \\
\hline Smoking & $12(33.3)$ \\
\hline Drinking alcohol & $4(11.1)$ \\
\hline Atrial fibrillation & $13(36.1)$ \\
\hline Previous stroke & $7(19.4)$ \\
\hline Mean glucose level \pm SD, mg/dL & $135.5 \pm 43.4$ \\
\hline Hemisphere (right) & $22(61.1)$ \\
\hline Aphasia & $16(44.4)$ \\
\hline Reperfusion therapy & $12(33.3)$ \\
\hline \multicolumn{2}{|l|}{ Stroke etiology } \\
\hline Cardioembolism & $12(33.3)$ \\
\hline Large-artery atherosclerosis & $11(30.5)$ \\
\hline Carotid dissection & 7 (19.5) \\
\hline Undetermined & $6(16.7)$ \\
\hline Carotid occlusion & $13(36.1)$ \\
\hline \multicolumn{2}{|l|}{ Infarct territory } \\
\hline MCA only & $26(72.2)$ \\
\hline MCA + ACA/PCA & $7(19.4)$ \\
\hline $\mathrm{MCA}+\mathrm{ACA}+\mathrm{PCA}$ & $3(8.3)$ \\
\hline \multicolumn{2}{|l|}{ Baseline ASPECTS } \\
\hline$>7$ & $8(22.3)$ \\
\hline$\leq 7$ & $24(66.6)$ \\
\hline \multicolumn{2}{|l|}{ ECASS score } \\
\hline $1-2$ & $11(30.5)$ \\
\hline$>2$ & $13(36.2)$ \\
\hline Mean baseline NIHSS score \pm SD & $17.41 \pm 6.0$ \\
\hline Mean craniectomy NIHSS score \pm SD & $22.08 \pm 5.81$ \\
\hline \multicolumn{2}{|l|}{ Baseline NIHSS score $1 \mathrm{a}$} \\
\hline Alert & $17(47.2)$ \\
\hline Nonalert & $19(52.7)$ \\
\hline \multicolumn{2}{|l|}{ Craniectomy NIHSS score $1 \mathrm{a}$} \\
\hline Nonalert & $36(100)$ \\
\hline \multicolumn{2}{|l|}{ Time from stroke to craniectomy } \\
\hline$<24 \mathrm{~h}$ & $16(44.4)$ \\
\hline $24-48 \mathrm{~h}$ & $13(36.1)$ \\
\hline $48-72 \mathrm{~h}$ & $6(16.7)$ \\
\hline$>72 \mathrm{~h}$ & $1(2.8)$ \\
\hline Retrospective consent & $32(88.9)$ \\
\hline Hypothermia & $6(16.7)$ \\
\hline
\end{tabular}

Values are presented as $n(\%)$, unless otherwise indicated. MCA, middle cerebral artery; ACA, anterior cerebral artery; PCA, posterior cerebral artery; ASPECTS, Alberta stroke program early CT score; ECASS, European Cooperative Acute Stroke Study; NIHSS, National Institutes of Health Stroke Scale.

shown). Ten patients (27.7\%) who underwent DHC achieved a modified Rankin score $\leq 3$ at the 1-year follow-up. Figure 2 shows outcome on modified Rankin scale at discharge as well as 6 and 12 months after stroke onset in this study compared to the analysis of Vahedi et al. [15]. Figure 3 shows Kaplan-Meier seizure-free curve after decompressive hemicraniectomy. 


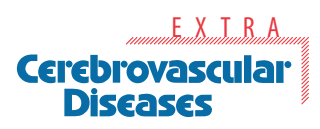

Fig. 1. Comparison chart showing the frequency of epileptic seizures and epilepsy after decompressive hemicraniectomy for malignant middle cerebral artery infarction among 3 studies: Brondani et al. (this study), Creutzfeldt et al. [16], and Santamarina et al. [17].

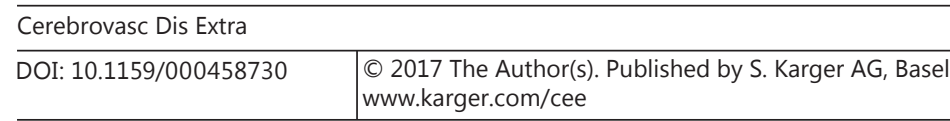

Brondani et al.: High Risk of Seizures and Epilepsy after DHC for Malignant MCA Stroke

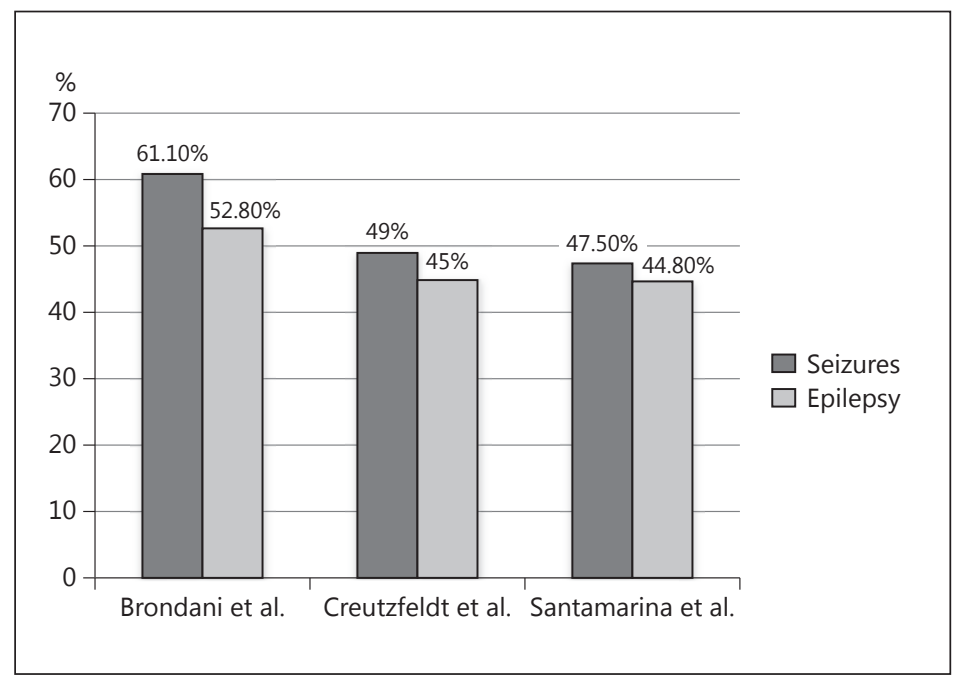

\section{Discussion}

We observed that seizures occurred in $22(61 \%)$ out of 36 patients. Out of 34 patients who survived the acute period, 19 (56\%) developed epilepsy after malignant MCA infarcts and DHC. These high rates are comparable to those reported by 2 recent studies which also examined this question [16, 17]. In our study, no variables were detected as risk factors for seizure or epilepsy development in this stroke subtype. Taken together, our results confirm that seizures or epilepsy are very frequent in patients with malignant MCA infarcts submitted to DHC, but no particular variable could be detected as a risk factor for their development.

To date, relatively few studies have reported frequencies of seizures or post-stroke epilepsy after malignant MCA infarcts submitted to DHC. The high proportion of seizures or epilepsy observed by us is in line with what has been previously reported in the literature $[16,17]$. However, since all data regarding seizure or post-stroke epilepsy in DHC MCA infarction are retrospective, and studies have evaluated a relatively small number of patients, these observed frequencies are in need of further confirmation in large prospective studies. Two randomized controlled multicenter trials for DHC after malignant MCA stroke were conducted: DESTINY (Decompressive Surgery for the Treatment of Malignant Infarction of the MCA) [20] and HAMLET (Hemicraniectomy after MCA Infarction with Life-Threatening Edema Trial) [21]. However, unfortunately, these studies did not report on risk factors for seizures or epilepsy, seizure or epilepsy incidence, timing of seizure onset, or the effect of seizures or epilepsy on mortality or patient quality of life. Thus, risk factors for post-stroke seizures or epilepsy as well as their magnitude and impact on morbidity, mortality, or patient quality of life need further confirmation from large prospective studies designed for this purpose.

Although DHC has proven to significantly reduce mortality, the degree of disability of its survivors has provoked an intense discussion in the literature [22-24]. This important question has been overlooked because most studies evaluated disability based exclusively on the Rankin scale. Few studies have evaluated other aspects of DHC for large MCA stroke, such as its impact in epilepsy development or in the quality of life of patients. In this area, Creutzfeldt et al. [16] retrospectively reviewed 55 patients submitted to DHC for malignant MCA infarcts. Twenty-seven (49\%) of these patients had seizures, and 25 (45\%) of them developed post-stroke epilepsy. These results are consistent with those recently reported by Santamarina et al. [17], who evaluated 80 patients and observed seizure occurrence in $47.5 \%$ of all 
Table 2. Variables according to seizure development

\begin{tabular}{|c|c|c|c|c|c|}
\hline Variables & $\begin{array}{l}\text { Seizure } \\
(n=22)\end{array}$ & $\begin{array}{l}\text { No seizure } \\
(n=14)\end{array}$ & OR & $95 \% \mathrm{CI}$ & $p$ \\
\hline Mean age $\pm S D$, years & $57.73 \pm 10.32$ & $60.86 \pm 14.26$ & - & - & 0.450 \\
\hline Female & $11(50)$ & $6(42.9)$ & 1.33 & $0.34-5.14$ & 0.742 \\
\hline White ethnicity & $21(95.5)$ & $12(85.7)$ & 0.29 & $0.02-3.49$ & 0.547 \\
\hline \multicolumn{6}{|l|}{ Vascular risk factors } \\
\hline Hypertension & $18(81.8)$ & $13(92.9)$ & 0.35 & $0.03-3.47$ & 0.628 \\
\hline Diabetes mellitus & $8(36.4)$ & $2(14.3)$ & 3.43 & $0.61-19.35$ & 0.255 \\
\hline Hypercholesterolemia & $3(13.6)$ & $3(21.4)$ & 0.58 & $0.10-3.38$ & 0.658 \\
\hline Smoking & $8(36.4)$ & $4(28.6)$ & 1.43 & $0.33-6.08$ & 0.727 \\
\hline Drinking alcohol & 0 & $4(28.6)$ & 0.31 & $0.19-0.52$ & 0.017 \\
\hline Atrial fibrillation & $6(27.3)$ & $7(50)$ & 0.37 & $0.09-1.53$ & 0.286 \\
\hline Previous stroke & $4(18.2)$ & $3(21.4)$ & 0.81 & $0.15-4.35$ & 1.000 \\
\hline Mean glucose level $\pm \mathrm{SD}, \mathrm{mg} / \mathrm{dL}$ & $130.7 \pm 50.2$ & $140.3 \pm 36.6$ & - & - & 0.685 \\
\hline Hemisphere (right) & $14(63.6)$ & $8(57.1)$ & 0.76 & $0.19-2.99$ & 0.482 \\
\hline Aphasia & $9(40.9)$ & $7(50)$ & 0.69 & $0.18-2.67$ & 0.734 \\
\hline Reperfusion therapy & $8(36.4)$ & $4(28.6)$ & 1.43 & $0.33-6.08$ & 0.727 \\
\hline Stroke etiology & & & - & - & 0.792 \\
\hline Cardioembolism & $6(27.3)$ & $6(42.9)$ & & & \\
\hline Atherothrombotic & $8(36.3)$ & $3(21.4)$ & & & \\
\hline Carotid dissection & $4(18.2)$ & $3(21.4)$ & & & \\
\hline Undetermined & $4(18.2)$ & $2(14.3)$ & & & \\
\hline Infarct territory & & & - & - & 0.411 \\
\hline MCA only & $18(81.8)$ & $8(57.1)$ & & & \\
\hline MCA + ACA/PCA & 3 (13.6) & $4(28.6)$ & & & \\
\hline $\mathrm{MCA}+\mathrm{ACA}+\mathrm{ACP}$ & $1(4.5)$ & $2(14.3)$ & & & \\
\hline Hemorrhagic transformation & $16(72.7)$ & $8(57.1)$ & 2.00 & $0.49-8.23$ & 0.471 \\
\hline \multicolumn{6}{|l|}{ ECASS score } \\
\hline $1-2$ & $6(27.2)$ & $5(35.7)$ & 3.00 & $0.62-14.47$ & 0.603 \\
\hline$>2$ & $10(45.5)$ & $3(21.4)$ & & & \\
\hline Mean baseline NIHSS score \pm SD & $18.2 \pm 6.8$ & $17.1 \pm 5.5$ & - & - & 0.636 \\
\hline Mean craniectomy NIHSS score \pm SD & $22.5 \pm 5.9$ & $21.4 \pm 5.8$ & - & - & 0.597 \\
\hline NIHSS score after 1 year & & & 1.20 & $0.31-4.60$ & 1.000 \\
\hline Alert & $10(45.5)$ & $7(50)$ & & & \\
\hline Nonalert & $12(54.6)$ & $7(49.9)$ & & & \\
\hline Time to craniectomy & & & & & 0.278 \\
\hline$<24 \mathrm{~h}$ & $8(36.4)$ & $8(57.1)$ & & & \\
\hline $24-48 \mathrm{~h}$ & $10(45.5)$ & $3(21.4)$ & & & \\
\hline $48-72 \mathrm{~h}$ & 4 (18.2) & $2(14.3)$ & & & \\
\hline$>72 \mathrm{~h}$ & $0(0.0)$ & $1(7.1)$ & & & \\
\hline Rankin score at discharge & & & 0.48 & $0.10-2.24$ & 0.467 \\
\hline $0-4$ & $8(36.4)$ & 3 (21.4) & & & \\
\hline$>4$ & $14(63.6)$ & $11(78.6)$ & & & \\
\hline Rankin score at 6 months & & & & & 1.000 \\
\hline $0-3$ & $5(22.7)$ & $4(28.6)$ & & & \\
\hline 4 & $9(40.9)$ & $3(21.4)$ & & & \\
\hline$>4$ & $7(31.8)$ & $7(50)$ & & & \\
\hline Mortality & $6(27.3)$ & $6(42.9)$ & 0.50 & $0.12-2.06$ & 0.471 \\
\hline
\end{tabular}

Values are presented as $n(\%)$, unless otherwise indicated. OR, odds ratio; CI, confidence interval; MCA, middle cerebral artery; ACA, anterior cerebral artery; PCA, posterior cerebral artery; ECASS, European Cooperative Acute Stroke Study; NIHSS, National Institutes of Health Stroke Scale. 
Brondani et al.: High Risk of Seizures and Epilepsy after DHC for Malignant MCA Stroke

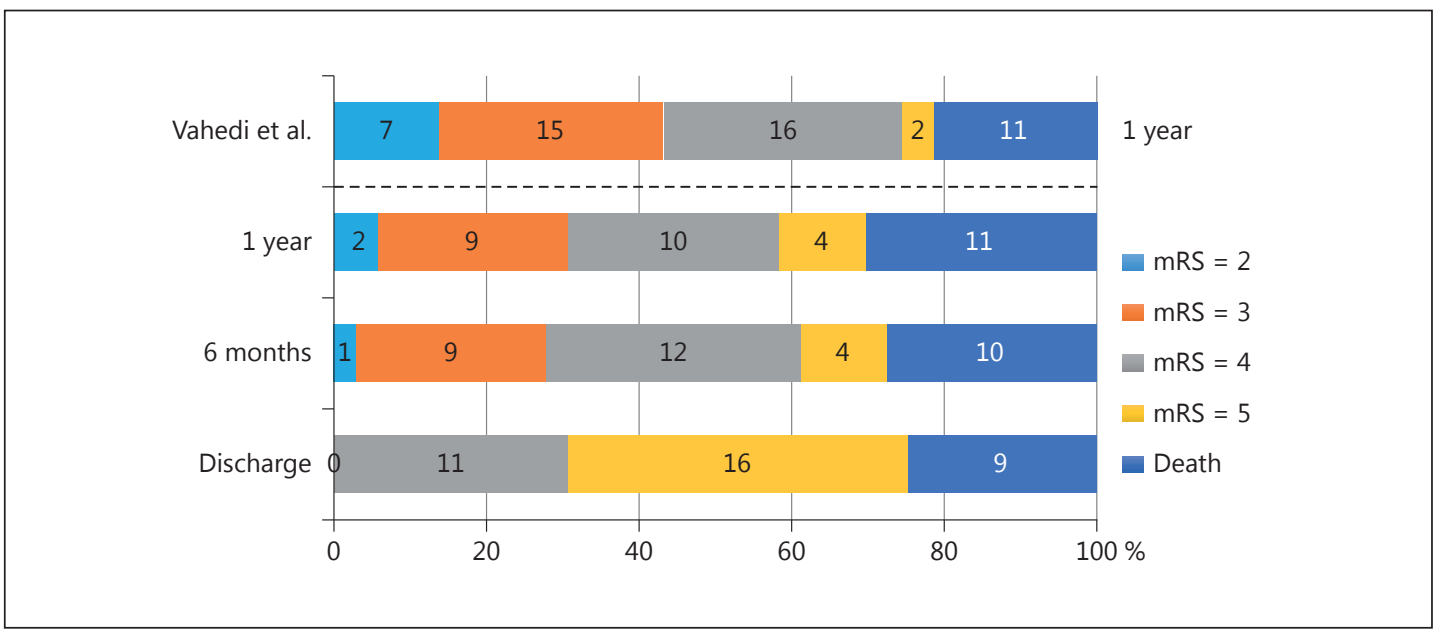

Fig. 2. Outcome on modified Rankin scale (mRS) at discharge as well as 6 and 12 months after stroke onset in this study. For comparision, the top bar shows the results for decompressive hemicraniectomy (DHC) in the pooled analysis of a previous multicenter randomized controlled trial of DHC for malignant middle cerebral artery stroke by Vahedi et al. [15].

Fig. 3. Kaplan-Meier seizure-free curve after decompressive hemicraniectomy for large middle cerebral artery ischemic stroke. Time zero is the time of stroke onset.

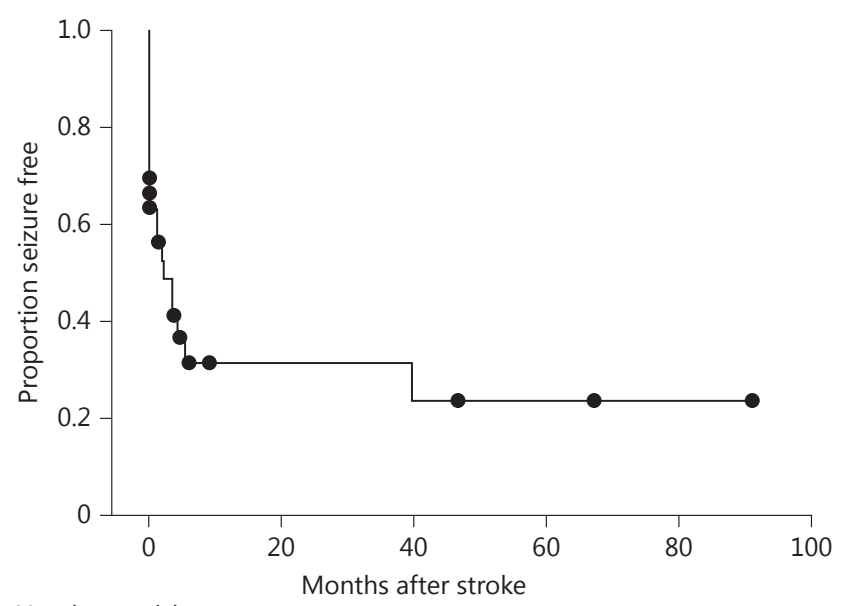

Number at risk

$\begin{array}{llllll}34 & 16 & 0 & 0 & 0 & 0\end{array}$

patients and in $53.7 \%$ of survivors. However, in contrast to our patients, who developed most seizures during the first week, in both these previous studies, the median time from stroke to first seizure were 222 and 221 days, respectively. On the other hand, the earlier seizure onset observed by us is compatible with other previous studies, where the highest risk for seizures in ischemic stroke patients without DHC was also observed within the first week and declined over the subsequent months [2]. This discrepancy in time until seizure onset between studies might perhaps be explained by the presence or absence of early anticonvulsant prophylaxis. Thus, it is possible that anticonvulsant prophylaxis can prevent acute seizures, but not epilepsy development in these patients. A similar situation is observed for seizures after trau- 
Brondani et al.: High Risk of Seizures and Epilepsy after DHC for Malignant MCA Stroke

matic brain injury, where evidence suggests that prophylactic anticonvulsants prevent early seizures but not late seizures or post-traumatic epilepsy [25]. Based on this evidence, the American Academy of Neurology recommend the use of anticonvulsant prophylaxis during the first weeks after traumatic brain injury [26]. Therefore, and considering the high prevalence of seizure or epilepsy after DHC for malignant MCA infarcts, it should be considered to recommend anticonvulsant prophylaxis in patients with malignant MCA stroke, at least for the first weeks during which patients are in acute critical period. Thus, prospective studies need to be conducted to evaluate potential benefits of anticonvulsant prophylaxis in DHC for malignant MCA stroke. Also, in our study, we could not observe a clear association of seizure with cranioplasty or clusters of seizure around the time of cranioplasty. Since the frequency of seizures observed in the studies is equally high, if there is an effect of cranioplasty on seizure or epilepsy development, it should be small. This is further supported by Walcott et al. [27], who estimated that cranioplasty would be responsible for increasing the risk of new seizures in only 3.3\% of patients. Creutzfeldt et al. [16] and Santamarina et al. [17] also studied several plausible variables as risk factors for seizures or epilepsy development after stroke. Male sex and timing of DHC were the only factors associated with an increased risk for seizure or epilepsy development after DHC for malignant MCA infarcts in these studies. In our study, we failed to observe any risk factor for seizure or epilepsy development after DHC for malignant MCA infarcts. However, as we performed DHC no longer than $72 \mathrm{~h}$ after stroke for all patients, except for 1 , with most patients treated before $48 \mathrm{~h}$, and since we studied a smaller number of patients, we could not appropriately evaluate the effect of timing of DHC on seizure onset. Also, we could not confirm that gender affects seizure predisposition. However, the question of gender in epilepsy has been studied in other situations. For example, in one study, Burneo et al. [28] reported that females failed more than males in becoming seizure-free after epilepsy surgery, a finding that was not confirmed by later observations $[29,30]$. Also, female [31] and male [32] sex were both associated with an increased predisposition to seizures or epilepsy after stroke, findings that could not be confirmed by posterior studies. Thus, the question whether timing of DHC or gender are risk factors for seizure or epilepsy development after DHC for malignant MCA infarcts is interesting but remains to be confirmed.

In our view, it is possible that no isolated risk factor for seizure or epilepsy can be easily identified in malignant MCA infarcts. We discuss here 3 possible explanations for this fact. First, the greatest risk factor for post-stroke seizures in DHC seems to be related with the large stroke volume and the large cortical involvement itself. Cortical involvement is a wellknown factor associated with post-stroke seizures [33]. In the DECIMAL trial (Decompressive Craniectomy in Malignant MCA Stroke) [34], the authors observed that $6(40 \%)$ of 15 patients developed seizures after DHC, but 2 (50\%) of 4 survivors without DHC also presented seizures, an observation suggesting that seizures or epilepsy are characteristics of the large MCA stroke area or volume and cannot be attributed solely to DHC. Second, the degree of inflammatory response must also be considered. Preclinical evidence suggests that there is an important inflammatory response after large MCA infarcts [35]. Recent evidence suggests an important role of inflammation in seizure or epilepsy development [36]. Thus, the inflammatory response that follows malignant MCA stroke might well have a role in seizure or epilepsy development in these patients. However, this inflammatory response is inherent to these large strokes and cannot be easily investigated. Finally, large middle cerebral infarction encompasses the motor cortex and might evolve to the temporal lobe as well, regions commonly involved in seizures or epilepsy [17]. These 3 characteristics are common to large MCA infarcts and may contribute significantly to seizure or epilepsy development, perhaps overshadowing other eventual clinical variables that could be investigated as risk factors for seizure or epilepsy in these patients. In our view, these aspects, associated with the relatively 
small number of patients included in the studies of seizures or epilepsy after DHC for malignant MCA infarcts so far, could explain the absence of clinical variables identified as predictors of seizures or epilepsy in these patients. Because of the significant rates of seizures and epilepsy in malignant MCA infarction and their implications for functional recovery and patient quality of life, we agree with other authors that it is perhaps time to consider strategies for preventing seizure or epilepsy development in this group of patients $[16,17]$. According to our observations, seizures might occur very early if patients are not submitted to seizure prophylaxis. In this context, seizures and epilepsy, as well as their treatment might have different prognostic results [37-39]. Thus, our results reinforce the need for prospective randomized and controlled trials for seizure prophylaxis and epilepsy treatment in these patients.

We recognize that our study has limitations. It has a retrospective design, with a relatively small sample size. In this scenario, negative results need to be interpreted with caution due to a lack of statistical power. However, our patients had similar seizure or epilepsy rates as those reported by other authors, and the functional outcome of patients overlaps with other studies of DHC for stroke with large samples. Thus, based on our results and those of the other 2 studies, seizures or epilepsy seem to be very common in patients treated with DHC for MCA stroke and protocols for their management need to be developed.

In summary, we confirmed a high incidence of seizures and epilepsy in malignant MCA infarcts and observed that seizures and epilepsy could occur precociously in patients who are not submitted to anticonvulsant prophylaxis. Considering the high rates of seizures and epilepsy in these patients, trials with anticonvulsant prophylaxis might be welcome. If anticonvulsant prophylaxis would not reduce epileptogenesis, it could reduce seizures during the first weeks, perhaps having a positive impact on mortality or functional recovery in this catastrophic form of stroke.

\section{Acknowledgments}

This study was fully supported by the Brazilian Government research grant agencies CNPq, FAPESP, and FAPERGS. M.B.M. is further supported by CNPq (\#485423/2012-0, \#307084/2014-0) and PRONEM-FAPERGS/CNPq (\#11/2043.0). The funders had no role in study design, data collection and analysis, decision to publish, or preparation of the manuscript.

\section{Disclosure Statement}

None of the authors has any conflict of interest to disclose.

\section{References}

1 Donnan GA, Fisher M, Macleod M, Davis SM: Stroke. Lancet 2008;371:1612-1623.

-2 So EL, Annegers JF, Hauser WA, O'Brien PC, Whisnant JP: Population-based study of seizure disorders after cerebral infarction. Neurology 1996;46:350-355.

-3 Bladin CF, Alexandrov AV, Bellavance A, Bornstein N, Chambers B, Cote R, Lebrun L, Pirisi A, Norris JW: Seizures after stroke: a prospective multicenter study. Arch Neurol 2000;57:1617-1622.

4 Lamy C, Domigo V, Semah F, Arquizan C, Trystram D, Coste J, Mas JL; Patent Foramen Ovale and Atrial Septal Aneurysm Study Group: Early and late seizures after cryptogenic ischemic stroke in young adults. Neurology 2003;60:400-404. 


\begin{tabular}{l|l}
\hline Cerebrovasc Dis Extra \\
\hline DOI: $10.1159 / 000458730$ & $\begin{array}{l}\text { C } 2017 \text { The Author(s). Published by S. Karger AG, Basel } \\
\text { www.karger.com/cee }\end{array}$ \\
\hline
\end{tabular}

Brondani et al.: High Risk of Seizures and Epilepsy after DHC for Malignant MCA Stroke

5 Krishnamurthi RV, Moran AE, Feigin VL, Barker-Collo S, Norrving B, Mensah GA, Taylor S, Naghavi M, Forouzanfar MH, Nguyen G, Johnson CO, Vos T, Murray CJ, Roth GA; GBD 2013 Stroke Panel Experts Group: Stroke prevalence, mortality and disability-adjusted life years in adults aged 20-64 years in 1990-2013: data from the Global Burden of Disease 2013 Study. Neuroepidemiology 2015;45:190-202.

6 Menon B, Shorvon SD: Ischaemic stroke in adults and epilepsy. Epilepsy Res 2009;87:1-11.

-7 Pitkänen A, Roivainen R, Lukasiuk K: Development of epilepsy after ischaemic stroke. Lancet Neurol 2015;15: 185-197.

8 Brodie MJ, Elder AT, Kwan P: Epilepsy in later life. Lancet Neurol 2009;8:1019-1030.

-9 Gensicke H, Seiffge DJ, Polasek AE, Peters N, Bonati LH, Lyrer PA, Engelter ST: Long-term outcome in stroke patients treated with IV thrombolysis. Neurology 2013;80:919-925.

10 LaRoche SM, Helmers SL: The new antiepileptic drugs: clinical applications. JAMA 2004;291:615-620.

11 Nadeau SE, Lu X, Dobkin B, Wu SS, Dai YE, Duncan PW; LEAPS Investigative Team: A prospective test of the late effects of potentially antineuroplastic drugs in a stroke rehabilitation study. Int J Stroke 2012;9:449-456.

12 Camilo 0, Goldstein LB: Seizures and epilepsy after ischemic stroke. Stroke 2004;35:1769-1775.

13 Huttner HB, Schwab S: Malignant middle cerebral artery infarction: clinical characteristics, treatment strategies, and future perspectives. Lancet Neurol 2009;8:949-958.

14 Hofmeijer J, van der Worp HB, Kappelle LJ: Treatment of space-occupying cerebral infarction. Crit Care Med 2003;31:617-625.

15 Vahedi K, Hofmeijer J, Juettler E, Vicaut E, George B, Algra A, Amelink, GJ, Schmiedeck P, Schwab S, Rothwell PM, et al: Early decompressive surgery in malignant infarction of the middle cerebral artery: a pooled analysis of three randomised controlled trials. Lancet Neurol 2007;6:215-222.

-16 Creutzfeldt CJ, Tirschwell DL, Kim LJ, Schubert GB, Longstreth WT Jr, Becker KJ: Seizures after decompressive hemicraniectomy for ischaemic stroke. J Neurol Neurosurg Psychiatry 2014;85:721-725.

-17 Santamarina E, Sueiras M, Toledo M, Guzman L, Torne R, Riveiro M, Quintana M, Salas Puig X, Sahuquillo J, Alvarez Sabin J: Epilepsy in patients with malignant middle cerebral artery infarcts and decompressive craniectomies. Epilepsy Res 2015;112:130-136.

-18 Fisher RS, Acevedo C, Arzimanoglou A, Bogacz A, Cross JH, Elger CE, Engel J Jr, Forsgren L, French JA, Glynn M, et al: ILAE official report: a practical clinical definition of epilepsy. Epilepsia 2014;55:475-482.

-19 Zweckberger K, Juettler E, Bosel J, Unterberg WA: Surgical aspects of decompression craniectomy in malignant stroke: review. Cerebrovasc Dis 2014;38:313-323.

20 Juttler E, Schwab S, Schmiedek P, Unterberg A, Hennerici M, Woitzik J, Witte S, Jenetzky E, Hacke W; DESTINY Study Group: Decompressive Surgery for the Treatment of Malignant Infarction of the Middle Cerebral Artery (DESTINY): a randomized, controlled trial. Stroke 2007;38:2518-2525.

21 Hofmeijer J, Kappelle LJ, Algra A, Amelink GJ, van Gijn J, van der Worp HB; HAMLET Investigators: Surgical decompression for space-occupying cerebral infarction (the Hemicraniectomy After Middle Cerebral Artery infarction with Life-threatening Edema Trial [HAMLET]): a multicentre, open, randomised trial. Lancet Neurol 2009;8:326-333.

22 Rahme R, Zuccarello M, Kleindorfer D, Adeoye OM, Ringer AJ: Decompressive hemicraniectomy for malignant middle cerebral artery territory infarction: is life worth living? J Neurosurg 2012;117:749-754.

-23 Juttler E, Unterberg A, Woitzik J, Bosel J, Amiri H, Sakowitz OW Gondan, M, Schiller P, Limprecht R, Luntz S, et al: Hemicraniectomy in older patients with extensive middle-cerebral-artery stroke. N Engl J Med 2014;370: 1091-1100.

24 Honeybul S, Ho KM, Blacker DW; ORACLE Stroke Study: Opinion regarding acceptable outcome following decompressive hemicraniectomy for ischemic stroke. Neurosurgery 2016;79:231-236.

25 Beghi E: Overview of studies to prevent posttraumatic epilepsy. Epilepsia 2003;44(suppl 10):21-26.

26 Chang BS, Lowenstein DH; Quality Standards Subcommittee of the American Academy of Neurology: Practice parameter: antiepileptic drug prophylaxis in severe traumatic brain injury: report of the Quality Standards Subcommittee of the American Academy of Neurology. Neurology 2003;60:10-16.

27 Walcott BP, Kwon CS, Sheth SA, Fehnel CR, Koffie RM, Asaad WF, Nahed BV, Coumans JV: Predictors of cranioplasty complications in stroke and trauma patients. J Neurosurg 2013;118:757-762.

28 Burneo JG, Black L, Martin R, Devinsky O, Pacia S, Faught E, Vasquez B, Knowlton RC, Luciano D, Doyle W, et al: Race/ethnicity, sex, and socioeconomic status as predictors of outcome after surgery for temporal lobe epilepsy. Arch Neurol 2006;63:1106-1110.

-29 Bianchin MM, Velasco TR, Martins AP, Sakamoto AC: Sex as a prognostic factor for surgical outcome in mesial temporal lobe epilepsy. Arch Neurol 2007;64:288-289.

-30 Burneo JG, Villanueva V, Knowlton RC, Faught RE, Kuzniecky, RI: Kaplan-Meier analysis on seizure outcome after epilepsy surgery: do gender and race influence it? Seizure 2008;17:314-319.

31 Kotila M, Waltimo O: Epilepsy after stroke. Epilepsia 1992;33:495-498.

-32 Giroud M, Gras P, Fayolle H, Andre N, Soichot P, Dumas R: Early seizures after acute stroke: a study of 1,640 cases. Epilepsia 1994;35:959-964.

-33 Zhang C, Wang X, Wang Y, Zhang JG, Hu W, Ge M, Zhang K, Shao X: Risk factors for post-stroke seizures: a systematic review and meta-analysis. Epilepsy Res 2014;108:1806-1816.

-34 Vahedi K, Vicaut E, Mateo J, Kurtz A, Orabi M, Guichard JP, Boutron C, Couvreur G, Rouanet F, Touze E, et al: Sequential-design, multicenter, randomized, controlled trial of early decompressive craniectomy in malignant middle cerebral artery infarction (DECIMAL Trial). Stroke 2007;38:2506-2517. 
-35 Chu HX, Kim HA, Lee S, Moore JP, Chan CT, Vinh A, Gelderblom M, Arumugam TV, Broughton BR, Drummond GR, Sobey CG: Immune cell infiltration in malignant middle cerebral artery infarction: comparison with transient cerebral ischemia. J Cereb Blood Flow Metab 2014;34:450-459.

36 Marchi N, Granata T, Janigro D: Inflammatory pathways of seizure disorders. Trends Neurosci 2014;37:55-65.

-37 Brüning T, Awwad S, Al-Khaled M: Do early seizures indicate survival of patients with nontraumatic intracerebral hemorrhage? Cerebrovasc Dis 2016;41:68-73.

38 Pezzini A, Grassi M, Del Zotto E, Giossi A, Volonghi I, Costa P, Poli L, Morotti A, Gamba M, Ritelli M, Colombi M, Padovani A: Complications of acute stroke and the occurrence of early seizures. Cerebrovasc Dis 2013;35: 444-450.

39 Consoli D, Bosco D, Postorino P, Galati F, Plastino M, Perticoni GF, Ottonello GA, Passarella B, Ricci S, Neri G, Toni D; EPIC Study: Levetiracetam versus carbamazepine in patients with late poststroke seizures: a multicenter prospective randomized open-label study (EpIC Project). Cerebrovasc Dis 2012;34:282-289. 